\title{
Current State of High 120 m Concrete Dam Bratsk Hydroelectric Power Plant
}

\author{
Mark A. Sadovich ${ }^{1}$, Tatyana F. Shlyakhtina ${ }^{1}$, Sofia M. Ginzburg ${ }^{2}$ and Alexander M. Yudelevich ${ }^{2}$ \\ 1. Department of Civil Engineering, Bratsk State University, Bratsk 665709, Russia; \\ 2. Department of Concrete and Reinforced Concrete Structure, Vedeneev VNIIG, St.Petersburg, 195220, Russia
}

\begin{abstract}
The research object was high $120 \mathrm{~m}$ concrete gravity dam of the Angara Bratsk hydroelectric power plant. The state of the concrete dam is estimated based on the results of continuous supervision performed by site personnel as well as periodic monitoring. According to the classification of the interrelations in the system "concrete-environment", there were selected some important parts of dams and a comprehensive analysis of concrete was executed on these parts. Concerning the complex research of concrete, a combination of full-scale tests with core-sampling has been proposed. Core samples tests had an object to study the deep concrete layers and to determine the specific indicators such as strength, density, porosity, comparative diameter of capillary pores, CaO content in cement stone and others. Obtained findings and recommended criteria can be applied when selecting technologies for constructing dams that guarantee their durability in the north.
\end{abstract}

Key words: Concrete gravity dam, hydroelectric power plant, monitoring.

\section{Introduction}

The state of the concrete dam is estimated based on the results of continuous supervision performed by site personnel as well as periodic monitoring. During 1995-2010, a modern program of monitoring of concrete dam which presents a complex of field and laboratory tests of concrete has been realized.

According to the classification of the interrelations in the system "concrete-environment", there were selected some important parts of dams and a comprehensive analysis of concrete was executed on these parts.

These characteristic parts, or zones, of dams are the following:

(1) submerged concrete of pressure column;

(2) interior zone;

(3) zone of variable water level in the upstream and downstream areas;

(4) exterior zone of the impermeable dams and of

Corresponding author: Mark A. Sadovich, doctor of science, professor; research field: monolithic concrete constructions. E-mail: sadovichma@mail.ru. power plant dams exposed to air;

(5) spillway zone exposed periodically to water effect.

Concerning the complex research of concrete, a combination of full-scale tests with core-sampling has been proposed.

Full-scale tests have included visual inspection, photographing and nondestructive tests of concrete.

Core samples have been tested to determine strength properties of concrete, pore structure, degree of cement hydration and the amount of free $\mathrm{CaO}$ in cement stone. Microscopic examination of a contact point of cement stone with aggregate filler was also fulfilled.

As for methodology, an idea of comparative tests of concrete in different operation conditions has been realized.

\section{Results of Nondestructive Tests}

The results of nondestructive tests of concrete supplemented with visual assessment have permitted to obtain a reliable description of the state of concrete surface of the dam parts being investigated. For exterior zones, it is the most important indicator of 
concrete stability after long time operation.

In this respect, the state of Bratsk dam concrete is as follows:

Concrete of pressure column: pressure column concrete examined by means of visual inspection and sclerometric tests using the interior inspection galleries has surface strength: $R=35 \mathrm{MPa}$ in the range of 19-60 MPa.

Surface strength of concrete moistened with constantly seeping filtrate or coated with calcite is: $R=$ 21.3 $\mathrm{MPa}$ in the range of 4-36 $\mathrm{MPa}$.

Thus surface being continuously moistened for many years with leaking filtrate is characterized preferably by lesser strength and can serve a model of seepage cracks surface

Variable water level zone concrete located in the upstream area of dams is subjected to variable moistening, frost attacks and other environmental factors.

Monolithic concrete of Bratsk dam pressure column located in zone of variable water level in the upstream area has been examined by means of surface ultrasound tests.

Test results have admitted to distinguish two main states of concrete:

- with no damages;

- having surface damage.

Appropriate statistical strength parameters of concrete without signs of destruction (Fig. 1a) are as follows:

$$
R=35.9 \mathrm{MPa}, S=9.0 \mathrm{MPa}, V=26 \% \text { (normal }
$$
distribution)

For damaged concrete, an asymmetric distribution curve is characteristic and the most probable strength is up to $10 \mathrm{MPa}$ (Fig. 1b). Reported damages are superficial and their amount is about $30 \%$ of the entire surface of the upstream face.

Concrete in variable water level zone of downstream face has been tested in the monolithic structures.

In the downstream area, damages of concrete of division walls surfaces are accumulated in the area of the most significant water level variations.

Depth of destroyed sections is up to $30 \mathrm{~cm}$. Concrete strength on the surface of concrete being destructed is 5 $+20 \mathrm{MPa}$, which is comparable to the strength of destructed concrete sections of the upstream face [1, 2].

Destruction of concrete in the downstream zone of variable water level, which is ice-free even in severe frosts, is typical of many northern dams.

The above mentioned conditions lead to multiple freezing and thawing even within one winter season, and at high frost concrete freezes in capillary rise zone. Thus, durability or persistence (including frost resistance) of concrete in the above mentioned zones has appeared to be exhausted during the reporting period of operation, and Bratsk hydrosystem has begun repair work on destroyed sectors.

\section{Full-Scale Tests}

Full-scale tests have generally provided the most important indicators of state of concrete surface of inspected zones of dams which were directly under impact of environment.

Core samples tests had an object to study the deep concrete layers and to determine the specific indicators, such as strength, density, porosity, comparative diameter of capillary pores, $\mathrm{CaO}$ content in cement stone and others.

Comparing the strength of the pressure column concrete $(200, \mathrm{~W}-8)$ and that of the interior zone (100+ $150, \mathrm{~W}-2$ ) at Northern dams has made it possible to combine them and get the common dependencies expressing influence of age on concrete strength (Table 1 and Fig. 2).

As for discrete method for concrete porosity determination, the test is reduced to the determination of water absorption in the set time ( $t=0 ; 0.25 ; 1 ; 24 \mathrm{hr})$.

To specify the parameters, designating the structure of pore space of cement stone by its water saturation curve, approximation of saturation dynamics with exponential dependence proposed by Brusser [3] has been applied: 


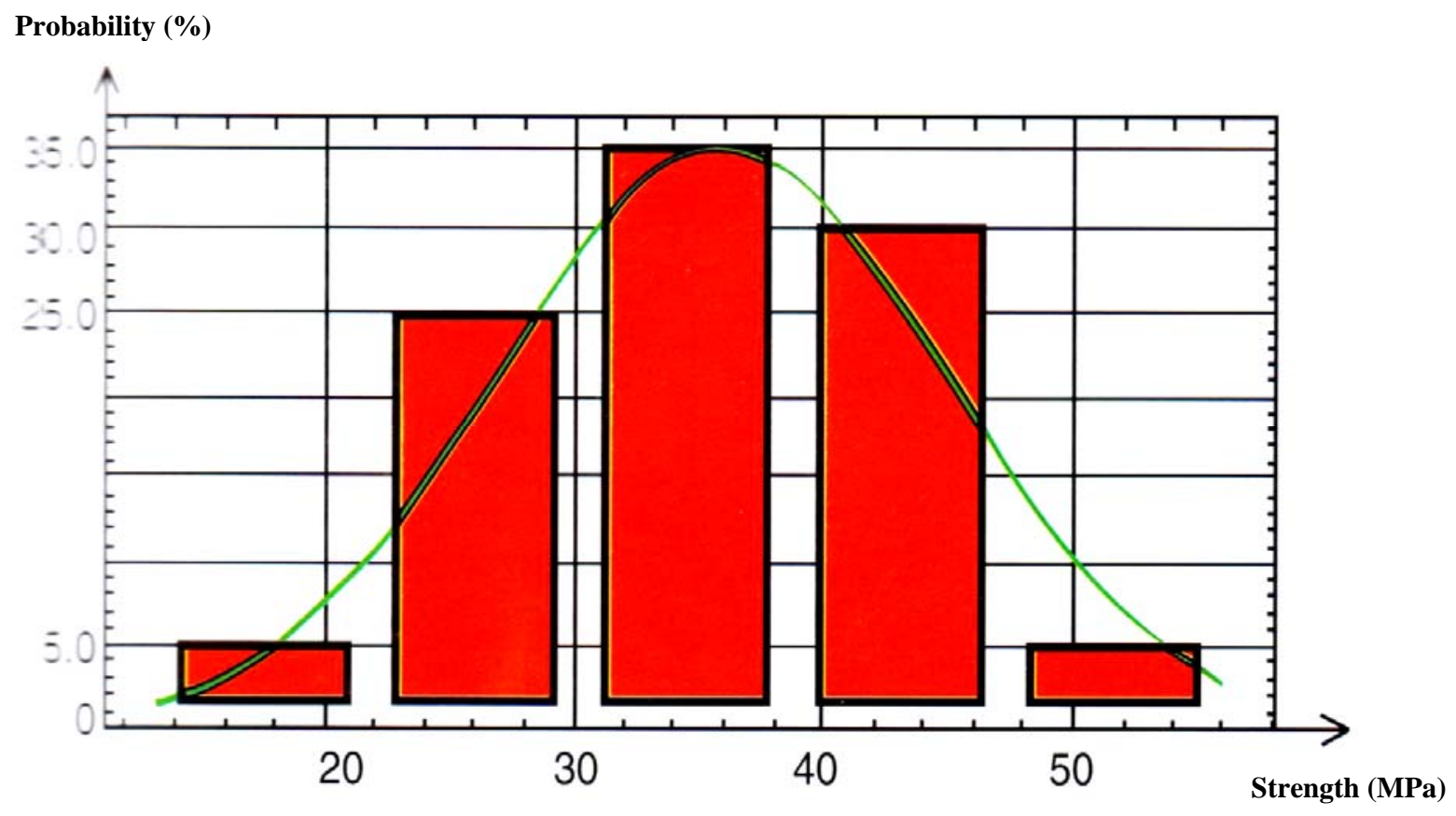

(a)

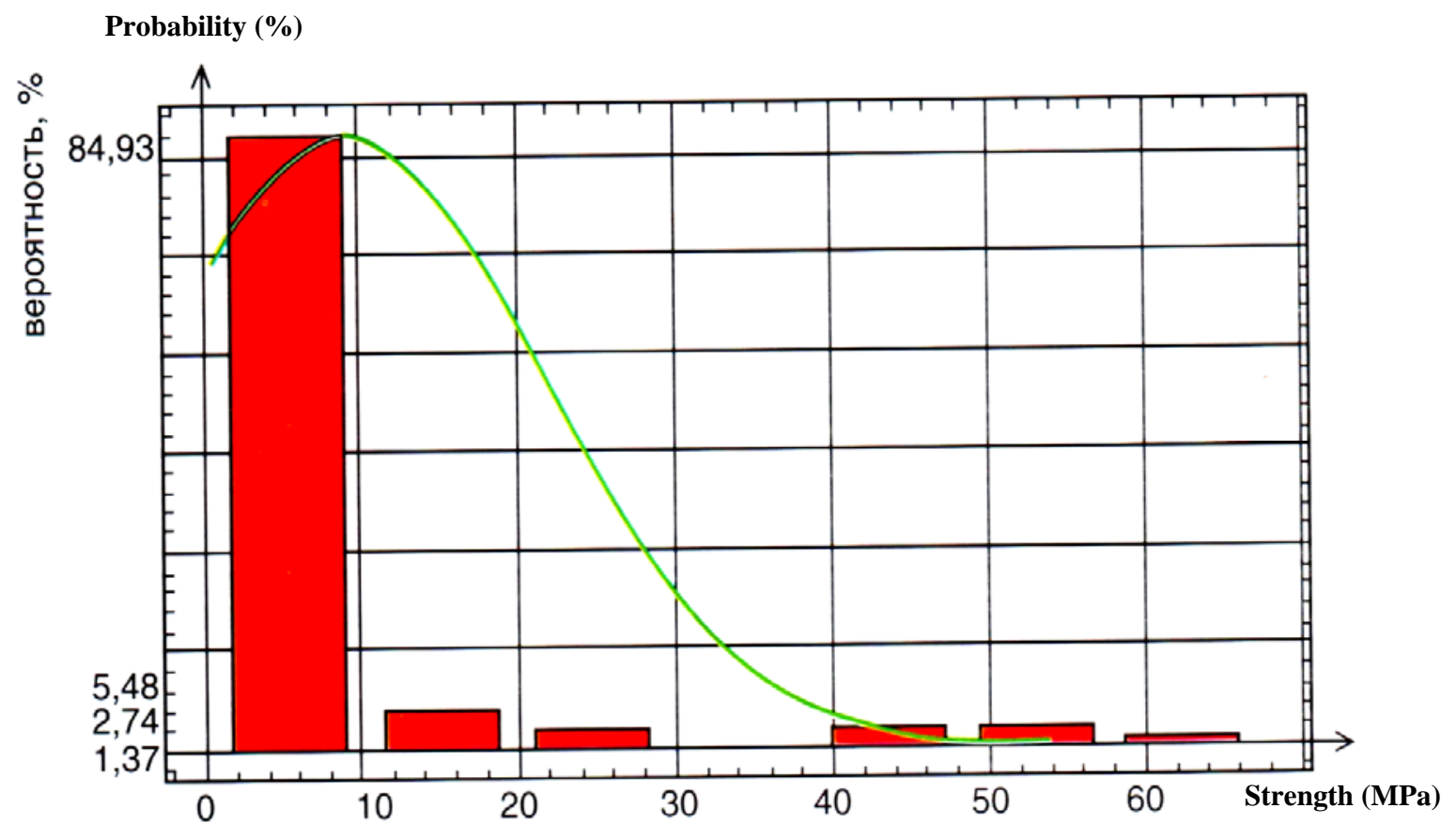

(b)

Fig. 1 Distribution bar chart of concrete strength of the upstream side of the Bratsk HPP dam: (a) initial stage, concrete without destruction; (b) final stage, destructed concrete. 
Table 1 Comparative data on concrete strength of northern dams.

\begin{tabular}{|c|c|c|c|c|c|}
\hline \multirow{3}{*}{ HPP construction } & \multirow{3}{*}{ Concrete grade } & \multicolumn{4}{|c|}{ Strength $(\mathrm{MPa})$} \\
\hline & & \multicolumn{2}{|c|}{ Control samples } & \multicolumn{2}{|c|}{ Aged cores (core of age) } \\
\hline & & 28 days & 180 days & Up to 5 years & $30-45$ years \\
\hline Bratsk & \multirow{4}{*}{$200, \mathrm{~W}-8$} & 21.0 & $31.6 / 18$ & 29.2/34 (2years) & $30.0 / 26$ (44years) \\
\hline Krasnoyarsk & & 21.0 & $32 / 22$ & $30.2 / 26$ (2years) & - \\
\hline Ust-Ilimsk & & 20.0 & $32 / 15$ & 43.0/24 (5years) & 33.6/32.8 (31years) \\
\hline Zeisk & & 17.0 & $27.4 / 14$ & $31.2 / 23$ (5years) & - \\
\hline Bratsk & \multirow{3}{*}{$100, \mathrm{~W}-2$} & 13.7 & $23.8 / 27$ & 26.3/32 (2years) & $22.5 / 28.5$ (44years) \\
\hline Zeisk & & 12.3 & $24.7 / 18$ & 27.6/26 (5years) & - \\
\hline Ust-Ilimsk & & 12.5 & $25.0 / 20$ & 39.0/23 (7years) & - \\
\hline
\end{tabular}

Note: coefficient of variation, \% after “/”.

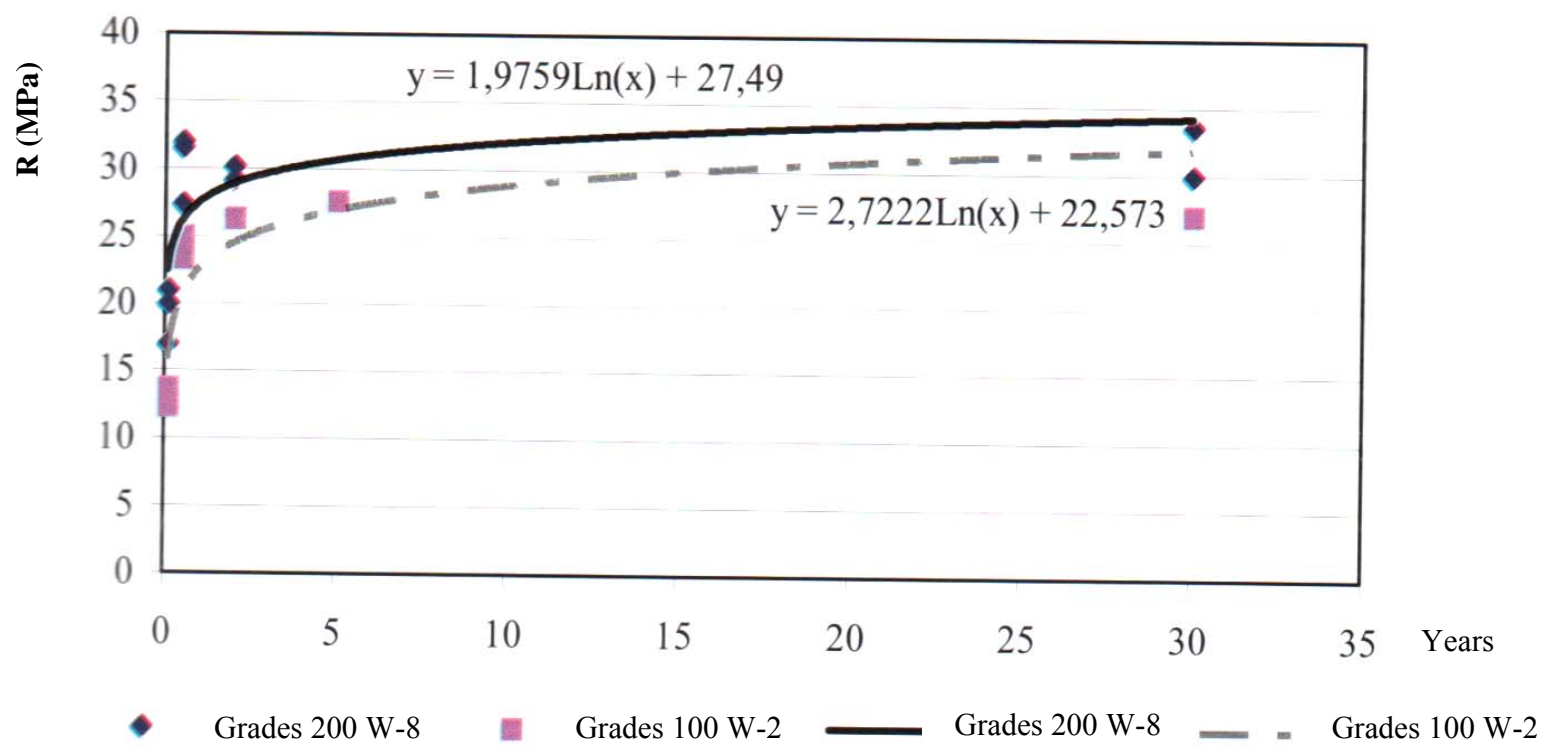

Fig. 2 Dependence on age of concrete strength (grades 200, W-8 and 100, W-2) of northern dams following the control samples tests results up to 180 days and cores-more than 180 days.

$$
W_{t}=W_{\max }\left[1-e^{-\left(\bar{\lambda}_{2} t\right) a}\right]
$$

where, $W_{t}$-water saturation of a sample in a time $t$; $W_{\max }$ - maximum water saturation; $\bar{\lambda}_{2}$-index of exponential degree equal to limit of ratio of acceleration related to saturation velocity; the value of this index indicates the average capillary radius; $a$-coefficient, characterizing the degree of capillary homogeneity in their semidiameters $(0<a<1)$. When $a=1$, all the capillaries have constant size.

Analysis of saturation dynamics with inherent ratio $W_{t} / W_{\max }$ depending on the core position relative to the external surfaces has permitted to identify zones significantly different in the average size of capillary pores.

Thus, the cores selected from downstream face surface count $\lambda_{2}=2.55$, which exceeds 2-4 times the same index for the deep concrete layers.

Thickness of the surface zone, which is characterized by above indicators, does not exceed $10 \mathrm{~cm}$.

For the deep layers, the coincidence of saturation curves has been registered, without reference to concrete grade.

Temperature and humidity conditions under which the dam exterior surfaces were formed and operated have affected capillary porosity so that the average capillary size significantly exceeds that of the deep 
concrete layers.

Besides that, the capillary porosity of the deep concrete layers determined experimentally has been compared with its calculated value according to Gorchakov formula taking into account variability of water content [4].

The comparison has revealed quite an exact match of results setting capillary porosity parameters: $X=9 \%, S$ $=1.5 \%$, where $X$ is the average value, $S$ is the standard deviation.

To evaluate the joint effect of porosity factor and cement-water ratio on concrete strength, a multiple regression analysis of the most representative test results of core samples of the pressure column has been performed at northern Bratsk and Ust-Ilimsk dams compared to southern Toktogul dam.

Regression component displays the impact of porosity variability on concrete strength.

Technological component displays the impact of variability of cement-water ratio on strength of concrete made at plant

The ability to transfer variability of water content and cement-water ratio of concrete made at plant on to concrete in the dam has been confirmed by coincidence of calculated and objective values of concrete porosity.

As it is shown in Table 2 and 3, the technological component of Toktogul concrete is within the boundaries of fluctuation variance of concrete made at plant, which confirms proximity of hardening conditions of south dams concrete to hardening conditions of control samples of concrete made at plant.

For northern dams, the influence of special temperature conditions of concrete hardening has reflected in the fact that the technological component of strength dispersion of the northern dam is persistently higher than that of concrete made at plant.

The component of cement variable activity reveals the level of technological discipline (to prevent mixing the different grades of cement), which is not enough high at north construction projects in the distance of cement industry.

Petrographic analysis of concrete transparent thin sections of Bratsk dam and of Krugobaykalskaya railway has been performed by an expert of Institute of the Earth's Crust, Siberian Branch of the Russian Academy of Sciences, Orlova G.V.

The main conclusion is that concretion of cement stone with aggregate grain surface observed at 50 -year-old concrete of Bratsk dam is also characteristic to the 100-year-old concrete of Krugobaykalskaya railway, for this last concretion of cement stone with small aggregate fractions has been registered, so that cement stone together with aggregate look like a rock base.

In our opinion, this consequence is of high importance as it gives hope for century-life of concrete of Russian northern dams (excluding surface

Table 2 Variance matrix of core strength.

\begin{tabular}{|c|c|c|c|c|}
\hline \multirow{4}{*}{ Dam } & \multicolumn{4}{|c|}{ Dispersion $(\mathrm{MPa}) 2$} \\
\hline & \multirow{3}{*}{ Regression component } & \multicolumn{3}{|c|}{ Rest dispersion } \\
\hline & & \multirow{2}{*}{ Overall } & \multicolumn{2}{|c|}{ Including } \\
\hline & & & Volatility of cement activity & Technological \\
\hline Ust-Ilimsk & $27.8 / 36 \%$ & $50.4 / 64 \%$ & $16.8 / 21.3 \%$ & $33.6 / 42.7 \%$ \\
\hline Bratsk & $7.92 / 23 \%$ & $27.2 / 77 \%$ & $9.07 / 25.6 \%$ & $18.13 / 51.4 \%$ \\
\hline Toktogul & $9-10 / 30 \%$ & $21.6 / 70 \%$ & $7.2 / 23.4 \%$ & $14.7 / 46.6 \%$ \\
\hline
\end{tabular}

Table 3 Variance matrix of control samples strength (180 days) of concrete made at plant.

\begin{tabular}{|c|c|c|c|c|}
\hline \multirow{2}{*}{ Concrete grade } & \multirow{2}{*}{ Cement type } & \multicolumn{3}{|c|}{ Dispersion $(\mathrm{MPa}) 2$} \\
\hline & & Volatility of cement activity & Technological component & Overall \\
\hline $200, \mathrm{~W}-8$ & $\begin{array}{l}\text { Slagportland cement of } \\
\text { Krasnoyarsk plant }\end{array}$ & $5-7 / 33.5 \%$ & $10-14 / 66.5 \%$ & $15-21 / 100 \%$ \\
\hline
\end{tabular}


zones) without any apprehension about its future.

\section{Corrosion at Points of Focused Seepage}

The first experience of operating Bratsk HPP under water pressure was impressive, as products of concrete leaching through seepage cracks and drains have formed a lot of picturesque stalactites decorating the arches of observation galleries (Figs. 3 and 4).

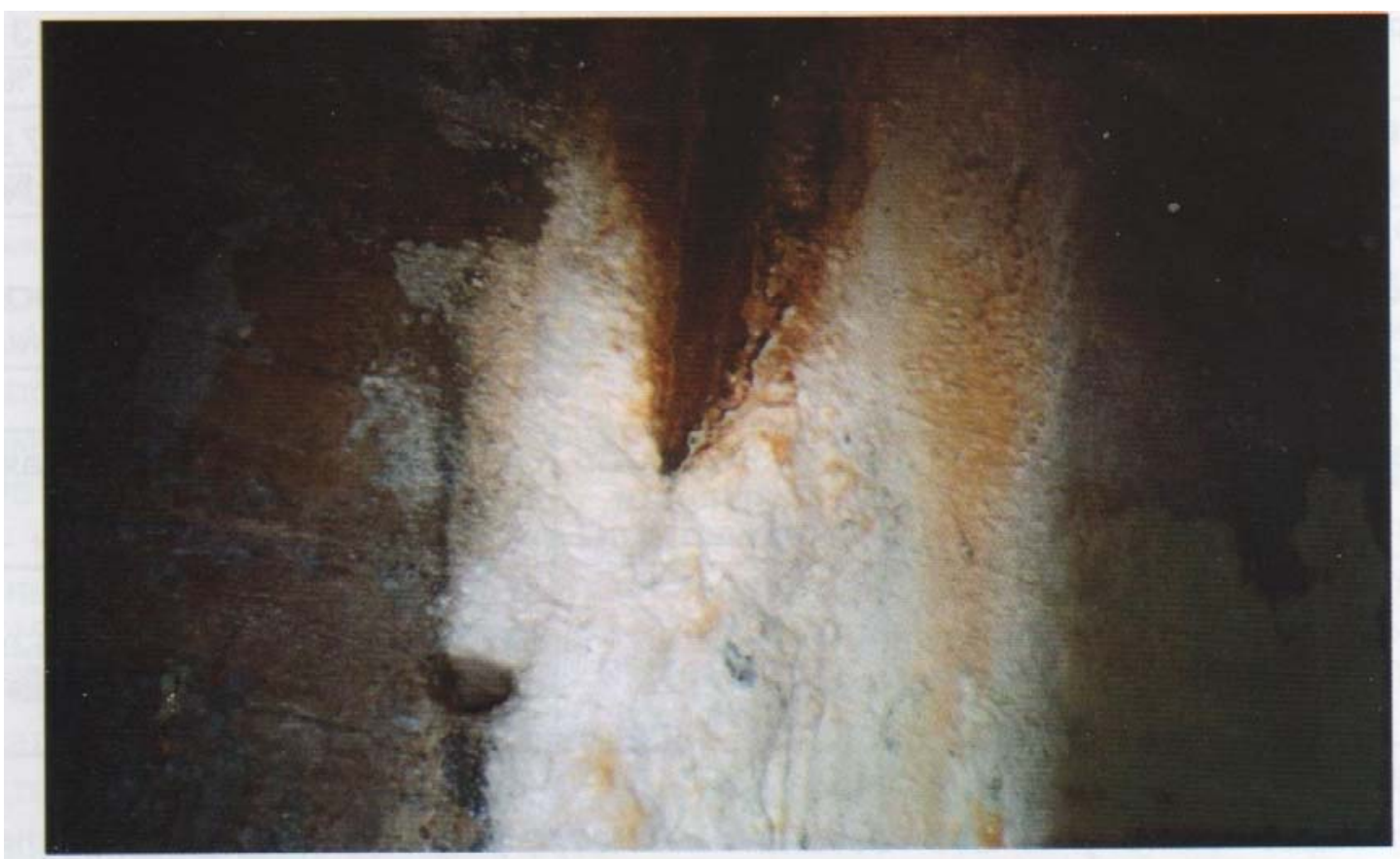

Fig. 3 Calcite sedimentation on an inspection gallery wall.

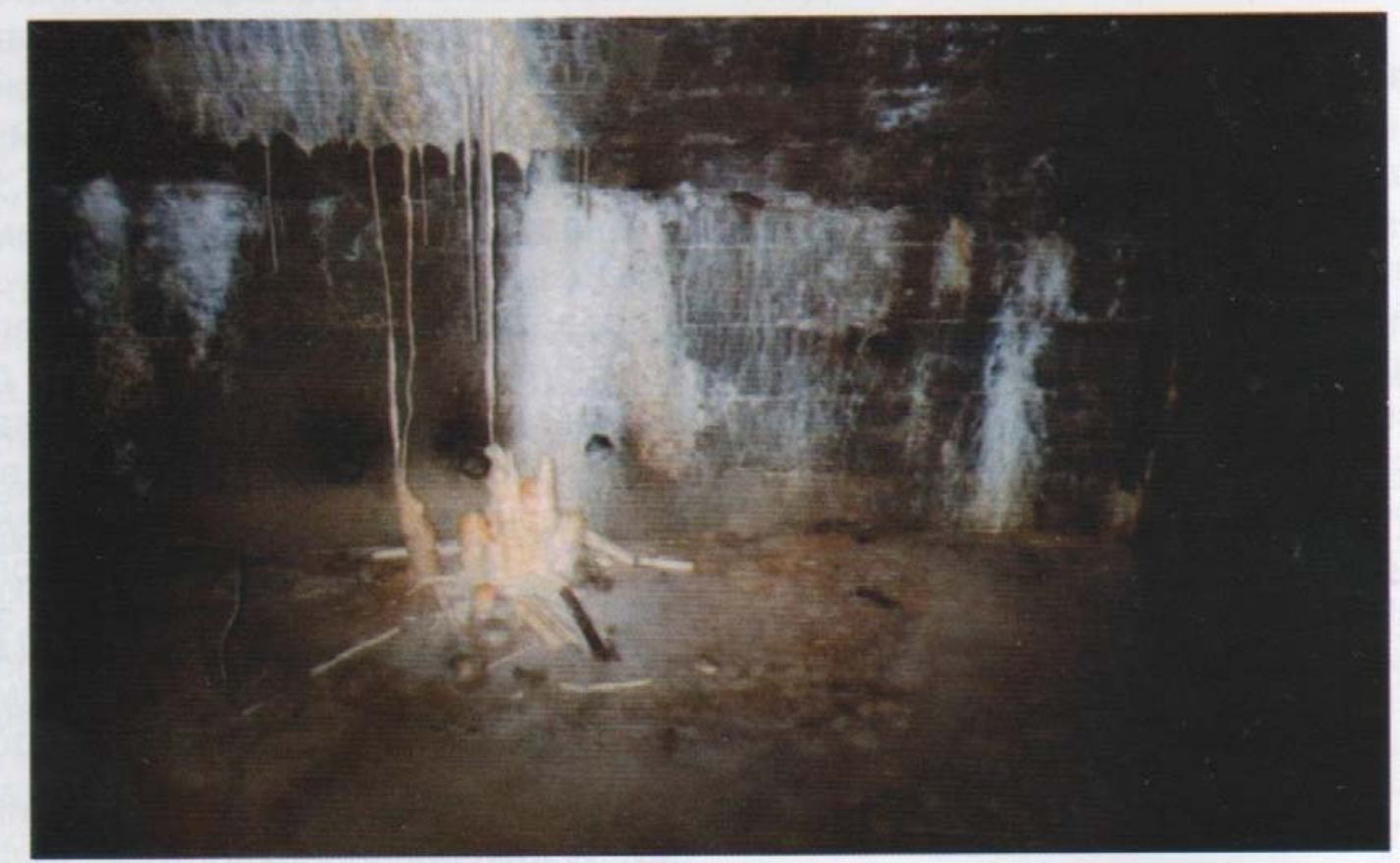

Рис. 4. Сталактиты и сталагмиты в смотровой галерее.

Fig. 4 Stalactites and stalagmites in an inspection gallery. 
According to calculations performed by K.V. Alekseev in 1976, waterfront concrete of Bratsk dam lost about 6 tons of calcium $(\mathrm{CaO})$ annually, and it had caused a serious concern that waterfront waterproofness could be damaged, because the above mentioned quantity had only covered the points of focused seepage.

Therefore, a problem of corrosion resistance of Angara dams concrete at points of focused seepage has been already raised since first years of Bratsk dam operation.

In recent years, a detailed study of characteristics of concrete corrosion at points of focused seepage has been fulfilled.

A technique of corrosion processes assessment based on correlation of chemical composition of reservoir water and that of filtrate (water leaked through the dam body).

According to general concept, the corrosion process relates with dissolution and leaching of calcium hydroxide out of concrete which is basic structure component of cement stone and which provides a high concrete alkalinity necessary for stable existence of the cement stone minerals (Baikov A.A., Moskvin V.M., Alekseev S.N.).

In fact, the analysis results have discovered that in about half of the cases, calcium ions were not leached but were deposited as a sediment during seepage through concrete, which means that the concentration of calcium ions in the filtrate is lower than in the water reservoir.

Dependencies of amount of leached ions on seepage discharge have been derived from the research results and these allow to conclude that calcium ions sedimentation predominates in seepage passages at discharge up to $0.005 \mathrm{~L} / \mathrm{min}$ [5].

When seepage discharge is in the range of 0.005 to $0.02 \mathrm{~L} / \mathrm{min}$ either sedimentation and leaching of calcium ions is registered.

It had also been specified that concentration of $\mathrm{Na}+$ $\mathrm{K}$ ions was persistently higher in the filtrate than in the water reservoir, regardless of the magnitude of seepage discharge. At high seepage discharge (over $0.02 \mathrm{~L} / \mathrm{min}$ ), leaching of either $\mathrm{Ca}^{2+}$ ions and $\mathrm{Na}^{+}, \mathrm{K}^{+}$occurs.

A predominating leaching of sodium compounds out of concrete has been observed for the first time, however, this fact is quite understandable.

Submerged concrete of Bratsk dam is composed of Portland-slag cement of Krasnoyarsk plant, containing up to $50 \%$ of Magnitogorsk blast-furnace granulated slag. The occurrence of alkaline oxides $\mathrm{Na}_{2} \mathrm{O}+\mathrm{K}_{2} \mathrm{O}$ in clinker $(1 \%)$ and in mineral supplements $(2 \%)$ specifies their content in cement.

Thus, cement comprising up to $50 \%$ of blast furnace slag the content of alkaline oxides is $1.0 \%-1.5 \%$ of cement bulk.

Sodium and potassium oxides being chemically much more active than calcium hydroxide, the process of their dissolution in seeping water overlays the general representation of cement stone corrosion.

Importantly, the degree of filtrate saturation with sodium and potassium ions depends on seepage discharge. Thus, seepage discharge being up to $0.02 \mathrm{~L} / \mathrm{min}$, the filtrate $\mathrm{pH}$ is increased to $10-12$ compared to 7-8 in the reservoir. Seepage discharge being higher such an abrupt increase of filtrate alkalinity is not observed.

The proposed model of corrosion process, which takes into account effect of sodium and potassium oxides, cannot be separated from seepage discharge, of which the value determines the concentration of soluble compounds.

$\mathrm{CaCO}_{3}$ sedimentation is only possible if filtrate is sufficiently saturated with sodium and potassium carbonates, that occurs in a varying degree when seepage discharge is about $0.02 \mathrm{~L} / \mathrm{min}$.

A further seepage discharge increase and a corresponding decrease of concentration of soluble cement stone components modifiy the corrosion process so that dissolution and leaching of both alkaline oxides and calcium hydroxide are bounded by the diffusion out of concrete of the above mentioned 
compounds.

Seepage discharge being more than $0.5 \mathrm{~L} / \mathrm{min}$, the increase of inspected ions concentration in filtrate compared to that in water reservoir is so light that it produces an illusion that there is no corrosion.

Obviously, such dangerous points of seepage in the dam require more precise control of ion concentration both in filtrate and water reservoir, in purpose not to lose a true representation of corrosion process.

The studies have made clear that the apprehension of loss of waterfront waterproofness as a result of concrete leaching was groundless because supplier of calcite was in large measure water reservoir.

Thus, calcite sediments occur not only on the walls of inspection galleries, but also directly in the seepage cracks. This has inevitably affected dynamics of seepage discharges, numerous of which have decreased abruptly to the moment.

\section{Frost Zones Resistance}

A feature of frost-resistant concrete of dam is the application of Portland-slag cement without additives following special technical conditions and its increased consumption ensuring cement-water ratio in designed compositions in the range of $0.4-0.5$.

Difference in concrete compositions of frost-resistant zones of dams consists in the increased consumption of cement in the downstream face concrete because when concreting the structures of downstream-looking division walls and walls those last were combined with the draught tubes for which the additional cavitation resistance requirements had been applied.

Frost-resistant zone of Bratsk dam represents a monolithic concrete with cement consumption $280 \mathrm{~kg} / \mathrm{m} 3$ with an average water content of concrete $\operatorname{mix} 145-150 \mathrm{~L} / \mathrm{m}^{3}$.

When determine capillary porosity, it is necessary to set $\alpha$-mount of chemically bound water. According to our data $\alpha=15 \%$ for applied Portland cement, then an average value of capillary porosity [4] is:

$$
\Pi=\frac{B-2 \alpha \amalg}{1000} \cdot 100=\frac{147-2 \cdot 0.15 \cdot 280}{1000} \cdot 100 \approx 6 \%
$$

Oscillation boundaries of porosity (with a confidence level $p=0.95)$, taking into account the regression are in the range of 3 up to $9 \%$.

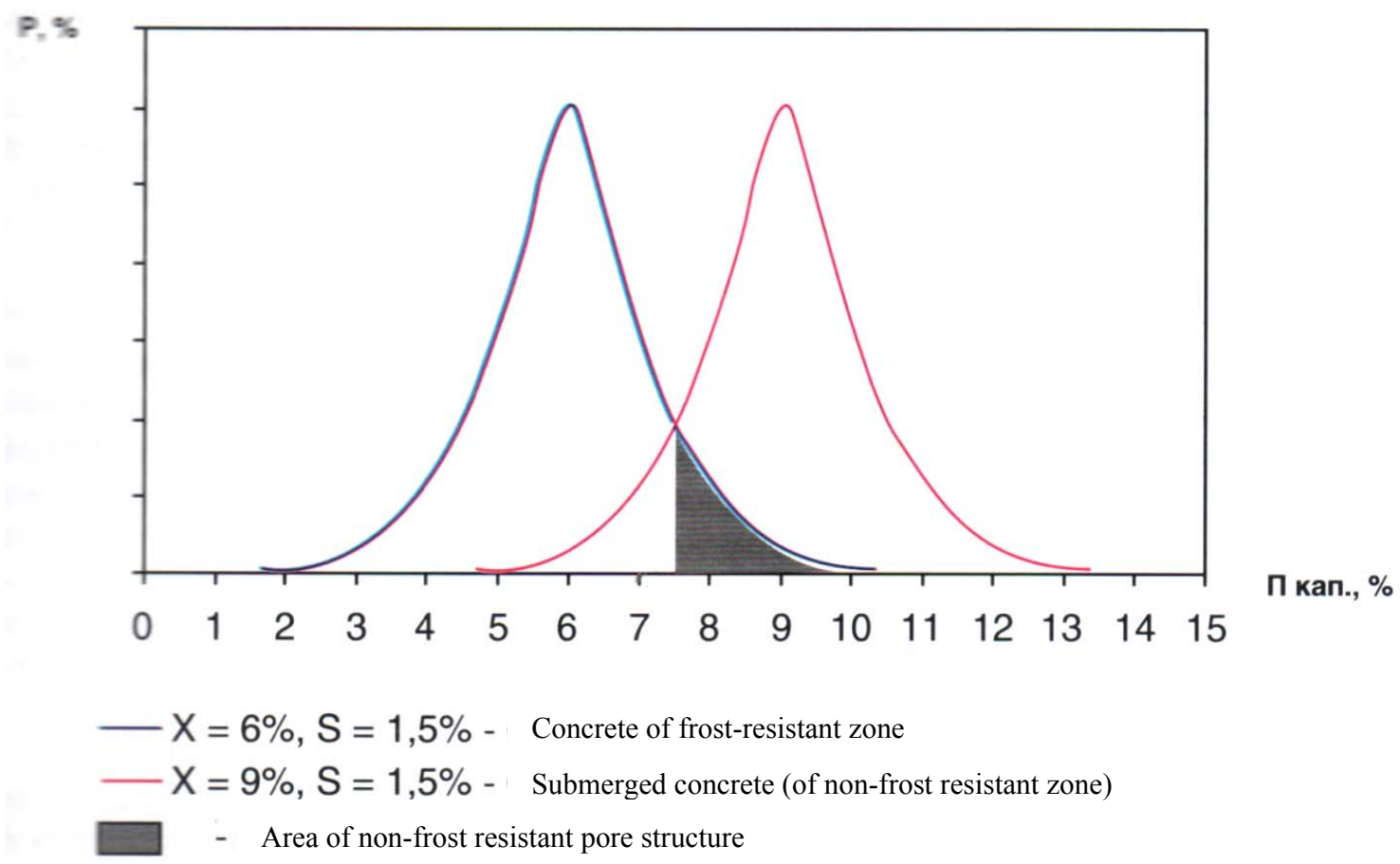

Fig. 5 Value distribution of the capillary porosity. 


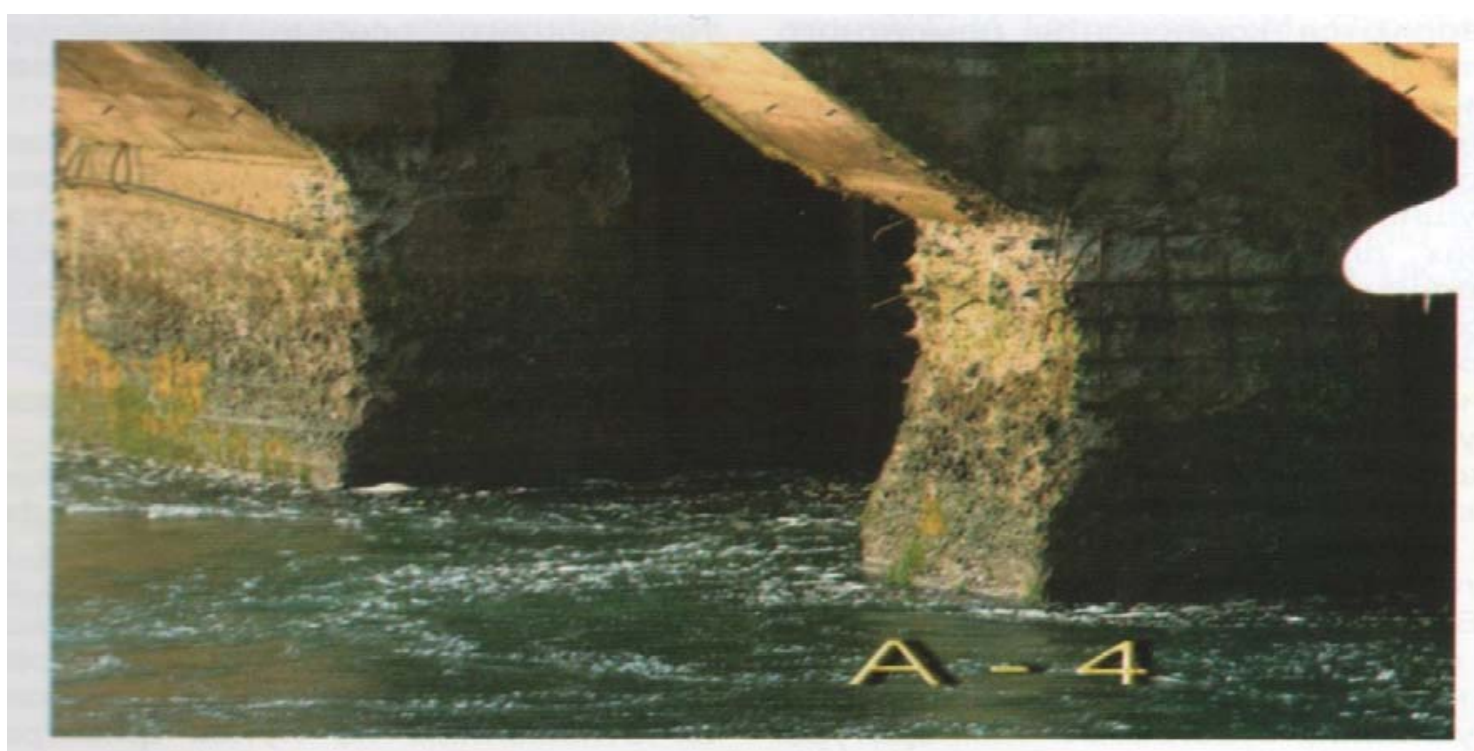

Fig. 6 Concrete destruction of downstream division walls of Bratsk HPP.

Distribution diagrams of capillary porosity values of frost-resistant and submerged concrete of pressure column (Fig. 5) evidently illustrate the variate correlation.

Frost-resistant concrete may have a pore structure of non-frost-resistant concrete with the probability that occurs in particular case, in our case $15 \%$.

So in our opinion, this fact explains an appearance of the areas with destructive signs on the surface of frost-resistant zone concrete of downstream face of dam (Fig. 6).

Thus, it should be admitted that for downstream operating conditions, the method applied had not provided the required durability of concrete. Ways to improve the method are the following:

- maintaining raised standards in frost resistance specification when developing concrete composition;

- applying method providing higher stability of basic parameters of concrete in the appointed dam area (including porosity) using an optimum combination of production factors framework.

\section{Conclusions}

Comprehensive researches of the Bratsk dam concrete body state after 50 years of operation in the North, lead to the general conclusions:
Direct water and air environment effect when dam is being operated is manifested at different depths, depending on combination of environmental factors.

A system of capillary pores formed at points of contact with air is distinct from that of the dam body. At points of contact with water, the cement stone components are dissolved. Both finally change strength and pore structure of concrete.

A mutual water and air effect in the downstream and upstream faces of dam is a source of manifestations of complex processes in concrete, which combine water saturation and freezing.

In some cases, particularly in the downstream face, there is destruction of concrete in certain areas due to sufficiently high probability (15\%) of non-frostresistant capillary porosity structure, among other factors.

Body dam concrete deprived of moisture rotation with the environment is under the most favorable conditions of stable temperature and humidity.

Strength increase of all northern dam concrete can be described by general logarithmic regression equation, whereby strength increase is slows down abruptly after 180 days.

Analysis of variance statistical series of concrete strength has revealed the influence of main production 
factors on strength instability:

- variable cement activity;

- technological component or variation cement-water ratio of concrete made at plant;

- thermal factor characterizing the specific thermal conditions of northern dam concrete.

Comparative petrographic analysis of recent concrete thin sections of Angara dams and of those of hundred-year-old concrete has revealed general coalescence processes of cement stone with an aggregate, which gives hope for the century-old existence of concrete dam (excluding surface areas) without any concern for its future.

Analysis of seepage discharge dynamics has made it possible to distinguish two main groups of seepage cracks according process nature: with decreasing discharge and with drifting discharge.

Autogenous healing of cracks by decreasing discharge is explained by deposition of calcite on the seepage pathways, the source of which is reservoir water. An indispensable condition for autogenous healing of cracks is the restriction on discharge amount (up to $0.15 \mathrm{~L} / \mathrm{min}$ ) per meter of a crack or per one drain.

As a criterion for waterfront concrete resistance, it is proposed to standardize strength and, as a consequence, density $R_{\min }(p=0.95) 25 \mathrm{MPa}$.

Obtained findings and recommended criteria can be applied when selecting technologies for constructing dams that guarantee their durability in the north.

\section{References}

[1] Sadovich M. A., Shlyakhtina T. F., and Solovyeva Z. I. 1999. "Distinctive Features of the Corrosion Processes in Waterfront Concrete of Bratsk HPP Dam." In Proceedings of Materials of the International Conference May 25-27, 1999 Moscow "Durability of structures and corrosion protection”, 264-71. (in Russian)

[2] Sadovich, M., and Shlyakhtina, T. 2003. "Strength of Concrete in Different Operational Media Concrete Solutions. Presented at the 1st International Conference on Concrete Repair,ST-Malo, France 15-17 July 2003.

[3] Brusser, M. I. 1983. "Development and Introduction of Statistical Methods for Concrete Strength Control." Presented at IX All-Union Conference on Concrete and Reinforced Concrete, 130-3. (in Russian)

[4] Gorchakov G. I., Kapkin, M. M., and Skramtaev B. G. 1965. Increase of Frost Resistance of Concrete in Constructions of Industrial and Hydraulic Structures. Moscow: Stroiizdat. (in Russian).

[5] Sadovich, M. A., and Sokolovskaya, A. A. 2002. "Corrosion Processes in Concrete of the Dams on the River Angara." In Proceedings of the International Seminar held at the University of Dundee, Scotland, UK on 5-6 September 2002. "Repair, Rejuvenation and Enhancement of Concrete”, 55-64. 